Pacific Journal of Mathematic 


\title{
A REPRESENTATION THEOREM FOR CERTAIN CONNECTED RINGS
}

\author{
Silvio Aurora
}

\begin{abstract}
It is shown that if $A$ is a semisimple, connected, locally connected $Q$-ring with unit element such that every maximal ideal disconnects $A$, then $A$ is continuously isomorphic to a dense subring of the ring of all continuous real-valued functions on a suitable compact Hausdorff space.
\end{abstract}

Many authors have obtained representations for semisimple Banach algebras as algebras of continuous functions. The object of this note is to present a somewhat similar result which, however, does not assume the presence of real or other kinds of scalars.

Specifically, it is established in Theorem 2 that if $A$ is a semisimple, connected, locally connected $Q$-ring with unit element such that every maximal ideal has a disconnected complement in $A$, then $A$ is continuously isomorphic to a dense subring of the ring $\mathscr{C}(\Phi ; \Re)$ of all continuous real-valued functions on a suitable compact Hausdorff space $\Phi$.

The basic tool employed is Theorem 1, which asserts that if $A$ is a connected, locally connected ring with unit element such that the removal of the zero element disconnects $A$, then $A$ is algebraically and topologically isomorphic to the field $R$ of real numbers.

The remarks contained in this note arose as tangential observations in connection with a somewhat different problem which was investigated with the financial support of the Research Council of Rutgers University; the author wishes to express his appreciation to the Research Council for that assistance.

2. Topological rings which are disconnected by the removal of a point. An important step in proving the representation theorem is the characterization of those locally connected rings which are disconnected by the removal of a point.

Theorem 1. Let $A$ be a topological ring with unit element. In order for $A$ to be algebraically and topologically isomorphic to the field $\mathfrak{R}$ of real numbers it is necessary and sufficient that $A$ be connected and locally connected, but that the set $A^{\#}$ of nonzero elements of $A$ be disconnected.

Proof. The necessity is obvious. 
For the sufficiency, we first note that the additive group of $A$ is algebraically and topologically isomorphic to the additive group of real numbers. (See for instance [1; Chap. 5, p. 28, Exercise 4], where a proof of the fact is outlined.) In particular, $A$ is locally compact.

If $c$ is a nonzero element of $A$ then the mapping $x \rightarrow c x$ is a continuous endomorphism of the additive group of $A$; thus, the image of $A$ under this mapping is a connected subgroup of that group and therefore coincides with $A$ since the image contains the nonzero element $c 1=c$. Then $1=c d$ for some $d$ in $A$, and $c$ is right invertible. It follows that $A$ is a division ring.

Pontrjagin's characterization of connected, locally compact division rings (see for instance [3; Chap. 6, p. 160, Corollary 2 of Theorem 1]) implies that $A$ is algebraically and topologically isomorphic to the field $\Re$ of real numbers, the field of complex numbers, or the division ring of real quaternions. The fact that $A^{\#}$ is disconnected eliminates the last two alternatives, and the theorem follows.

In order to obtain the representation theorem we shall employ a succession of simple lemmas. The first two of these lemmas follow. The proofs are routine.

Lemma 1. If $A$ is a connected ring with unit element then every left ideal and every right ideal of $A$ is connected.

Lemma 2. Let $A$ be a connected, locally connected ring with unit element, and let $I$ be a closed ideal which disconnects $A$. Then $A / I$ is algebraically and topologically isomorphic to $\Re$.

3. The representation theorem. If $\Phi$ is a compact Hausdorff space then the symbol $\mathscr{C}(\Phi ; \Re)$ will denote the ring of all continuous real-valued functions on $\Phi$, with the topology of uniform convergence on $\Phi$ as the topology of the ring. It is recalled that a topological ring with unit element is a Q-ring provided that the set of invertible elements is open; in a $Q$-ring with unit element, maximal ideals exist and are closed sets.

THEOREM 2. Let $A$ be a semisimple, connected, locally connected Q-ring with unit element such that every maximal ideal disconnects $A$. Then there exists a compact Hausdorff space $\Phi$ such that there is a continous isomorphism $\sigma$ of $A$ onto a dense subring of $\mathscr{C}(\Phi ; \Re)$.

The proof is outlined by listing the lemmas which are employed to construct it. 
Lemma 3. There is a subfield $P$ of $A$ such that $P$ contains 1 and $P$ is algebraically isomorphic to the field of rational numbers.

Proof. If $n$ is a natural number then no maximal ideal $M$ can contain $n$ since otherwise $A / M$, which is isomorphic to $\Re$ by Lemma 2 , would have finite characteristic. Thus, every natural number $n$ is an invertible element of $A$. If $P$ is the set of all elements of $A$ of the form $m n^{-1}$, with $m$ an integer and $n$ a natural number, then $P$ clearly is the required field.

Definition. A subset $C$ of a ring $A$ is said to be symmetric provided that whenever $x$ is in $C$ then $-x$ is in $C$.

Lemma 4. If $r$ is a positive rational number then there is a connected symmetric neighborhood $W$ of zero in $A$ such that $\varphi(W) \subset]-r, r[$ for every continuous nonzero homomorphism $\varphi$ of $A$ into $\Re$.

Proof. Since $-r$ is invertible there is a neighborhood $U$ of $-r$ which contains only invertible elements. Thus, $U$ is disjoint from every maximal ideal $M$, and $r+U$ is therefore disjoint from $r+M$ for every maximal ideal $M$.

There is a connected neighborhood $V$ of zero contained in the symmetric neighborhood $(r+U) \cap(-(r+U))$ of zero, so that $W=$ $V \cup(-V)$ is a connected symmetric neighborhood of zero which is contained in $(r+U) \cap(-(r+U))$ and therefore in $r+U$. It follows that $W$ is disjoint from $r+M$ for every maximal ideal $M$.

Let $\varphi$ be a continuous nonzero homomorphism of $A$ into $\Re$. Then the kernel of $\varphi$ must be a maximal ideal $M$ because the image of $\varphi$ is necessarily the entire field $\Re$. Now $r+M$ is disjoint from $W$, so that $r$ does not belong to $\varphi(W)$. We conclude that $\varphi(W) \subset]-r, r[$ since $\varphi(W)$ is a connected symmetric set of real numbers and does not contain $r$.

This proves the lemma.

Lemma 5. The relative topology of $P$ in $A$ is the ordinary topology of the field of rational numbers.

The proof involves a routine application of Lemma 4 .

Lemma 6. Let $U$ be a neighborhood of zero in $A$, and let $f$ be a continuous nonconstant mapping of $U$ into $\mathfrak{R}$ such that

$$
f\left(x_{1}+\cdots+x_{n}\right)=f\left(x_{1}\right)+\cdots+f\left(x_{n}\right)
$$


whenever $x_{1}, \cdots, x_{n}, x_{1}+\cdots+x_{n}$ belong to $U$, and $f(x y)=f(x) f(y)$ whenever $x, y, x y$ belong to $U$. Then there exists exactly one continuous nonzero homomorphism $\varphi$ of $A$ into $\mathfrak{R}$ such that the restriction of $\phi$ to $U$ is precisely $f$.

Proof. If $x$ is in $A$ then there is a natural number $m$ such that $x / r$ is in $U$ whenever $r$ is a natural number with $r \geqq m$. We define $\varphi(x)=m f(x / m)$. Then $\varphi$ is well-defined, and the remaining details of the proof are routine.

LEMMA 7. Let $W$ be a connected symmetric neighborhood of zero in $A$ such that $\varphi(W) \subset]-1,1[$ for every continuous nonzero homomorphism $\varphi$ of $A$ into $\Re$. Let $\Phi$ be the space of all continuous nonzero homomorphisms of $A$ into $\Re$, with the topology for $\Phi$ obtained by identifying $\Phi$ (in the obvious way) with a subset of the topological product of the family $\left\{I_{x} \mid x \in W\right\}$, where each space $I_{x}$ is the closed interval $[-1,1]$. Then $\Phi$ is a compact Hausdorff space.

We note that Lemma 6 implies that $\Phi$ can also be identified with the set of all continuous nonconstant mappings $f$ of $W$ into $\Re$ which have the properties that $f\left(x_{1}+\cdots+x_{n}\right)=f\left(x_{1}\right)+\cdots+f\left(x_{n}\right)$ whenever $x_{1}, \cdots, x_{n}, x_{1}+\cdots+x_{n}$ belong to $W$, and $f(x y)=f(x) f(y)$ whenever $x, y, x y$ belong to $W$. It may be noted that the topology for $\Phi$ has as a subbase the family of all sets

$$
\left\{\varphi_{0} ; x ; \varepsilon\right\}=\left\{\varnothing|\varphi \in \Phi,| \varphi(x)-\varphi_{0}(x) \mid<\varepsilon\right\},
$$

where $\varphi_{0} \in \Phi, x \in A$, and $\varepsilon$ is a positive real number. Furthermore, if $x$ is an arbitrary element of $A$ then there is a natural number $m$ such that $x / m \in W$; thus, every set $\left\{\varphi_{0} ; x: \varepsilon\right\}$ can also be written in the form $\left\{\varphi_{0} ; x / m ; \varepsilon / m\right\}$, so that there is a subbase for the topology of $\Phi$ which consists of all sets of the form $\left\{\varphi_{0} ; y ; \delta\right\}$, with $\varphi_{0} \in \Phi, y \in W$, and $\delta$ a positive real number. The proof of Lemma 7 then becomes routine.

Lemma 8. If $x$ is an element of $A$ then the function $\hat{x}$ defined on $\Phi$ by the rule $\hat{x}(\varphi)=\varphi(x)$, for all $\phi$ in $\Phi$, is a continuous realvalued function on $\Phi$.

The proof is routine.

Lemma 9. Let $\sigma$ be the mapping of $A$ into $\mathscr{C}(\Phi ; \Re)$ defined by the rule $\sigma(x)=\widehat{x}$ for all $x$ in $A$. Then $\sigma$ is a continuous isomorphism of $A$ into $\mathscr{C}(\Phi ; \Re)$. 
An application of Lemma 4 establishes the continuity of $\sigma$, while the fact that $\sigma$ is an isomorphism is proved in a routine manner.

Lemma $10 . \quad \sigma(A)$ is dense in $\mathscr{C}(\Phi ; \Re)$.

Proof. The closure of $\sigma(A)$ is a uniformly closed subring of $\mathscr{C}(\Phi ; \Re)$ which contains all constant real-valued functions on $\Phi$ since it contains all constant rational-valued functions on $\Phi$. It is also clear that the closure of $\sigma(A)$ separates points of $\Phi$, and the StoneWeierstrass Approximation Theorem (see for instance [2; p. 56, Th. 3]) implies that the closure of $\sigma(A)$ coincides with $\mathscr{C}(\Phi ; \Re)$.

This sequence of lemmas establishes the theorem.

An example demonstrates that the conclusion of Theorem 2 can not be sharpened. If $A$ is the set of all real-valued functions which are defined and have a continuous derivative on $[0,1]$, with the obvious operations in $A$, and with the norm for $A$ defined by

$$
N(x)=\sup \{|x(t)| \mid 0 \leqq t \leqq 1\}+\sup \left\{\left|x^{\prime}(t)\right| \mid 0 \leqq t \leqq 1\right\}
$$

for each $x$ in $A$, then $A$ is a commutative Banach algebra which clearly satisfies the hypothesis of Theorem 2. However, the topology for $A$ is strictly finer than the topology for $\mathscr{C}(\Phi ; \Re)$ in this example. For instance, if $x_{n}(t)=(2 \pi n)^{-1} \sin 2 \pi n t$ for $0 \leqq t \leqq 1$ whenever $n$ is a natural number, then the sequence $\left\{x_{n}\right\}$ converges uniformly to zero (that is, $\left\{x_{n}\right\}$ converges to 0 in $\mathscr{G}(\Phi ; \Re)$ ), but $\left\{x_{n}\right\}$ does not converge to zero in $A$ since $N\left(x_{n}\right)=(2 \pi n)^{-1}+1$ for every natural number $n$. Thus, $\sigma$ is not a homeomorphism of $A$ with $\sigma(A)$.

The same example also shows that $\sigma(A)$ need not coincide with $\mathscr{C}(\Phi ; \Re)$ even though $\sigma(A)$ is a dense connected subring of the latter. For instance, the element $z$ of $\mathscr{C}(\Phi ; \Re)$, where $z(t)=|t-(1 / 2)|$ whenever $0 \leqq t \leqq 1$, is obviously not the image of an element of $A$.

\section{REFERENCES}

1. N. Bourbaki, “Topologie générale," Chap. 5-6, 3rd ed., Éléments de mathématique, Hermann, Paris, 1963.

2. - Topologie générale, Chap. 10, 2nd ed., Éléments de mathématique, Hermann, Paris, 1961.

3. — Algèbre commutative, Chap. 5-6, Éléments de mathématique, Hermann, Paris, 1964.

Received April 28, 1969. 



\title{
PACIFIC JOURNAL OF MATHEMATICS
}

\author{
EDITORS
}

\author{
H. ROYDEN \\ Stanford University \\ Stanford, California \\ RICHARD PIERCE \\ University of Washington \\ Seattle, Washington 98105
}

\author{
J. DUGUNDJI \\ Department of Mathematics \\ University of Southern California \\ Los Angeles, California 90007 \\ BASIL GORDON \\ University of California \\ Los Angeles, California 90024
}

\section{ASSOCIATE EDITORS}

E. F. BECKENBACH
B. H. NeumanN

F. WOLF
K. YoshidA

\section{SUPPORTING INSTITUTIONS}

\author{
UNIVERSITY OF BRITISH COLUMBIA \\ CALIFORNIA INSTITUTE OF TECHNOLOGY \\ UNIVERSITY OF CALIFORNIA \\ MONTANA STATE UNIVERSITY \\ UNIVERSITY OF NEVADA \\ NEW MEXICO STATE UNIVERSITY \\ OREGON STATE UNIVERSITY \\ UNIVERSITY OF OREGON \\ OSAKA UNIVERSITY \\ UNIVERSITY OF SOUTHERN CALIFORNIA
}

\author{
STANFORD UNIVERSITY \\ UNIVERSITY OF TOKYO \\ UNIVERSITY OF UTAH \\ WASHINGTON STATE UNIVERSITY \\ UNIVERSITY OF WASHINGTON

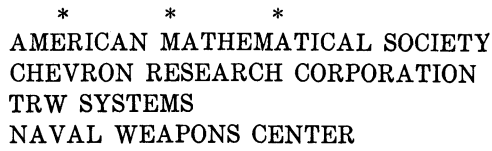

The Supporting Institutions listed above contribute to the cost of publication of this Journal, but they are not owners or publishers and have no responsibility for its content or policies.

Mathematical papers intended for publication in the Pacific Journal of Mathematics should be in typed form or offset-reproduced, double spaced with large margins. Underline Greek letters in red, German in green, and script in blue. The first paragraph or two must be capable of being used separately as a synopsis of the entire paper. It should not contain references to the bibliography. Manuscripts, in duplicate if possible, may be sent to any one of the four editors. Please classify according to the scheme of Math. Rev. 36, 1539-1546. All other communications to the editors should be addressed to the managing editor, Richard Arens, University of California, Los Angeles, California, 90024.

50 reprints are provided free for each article; additional copies may be obtained at cost in multiples of 50 .

The Pacific Journal of Mathematics is published monthly. Effective with Volume 16 the price per volume (3 numbers) is $\$ 8.00$; single issues, $\$ 3.00$. Special price for current issues to individual faculty members of supporting institutions and to individual members of the American Mathematical Society: $\$ 4.00$ per volume; single issues $\$ 1.50$. Back numbers are available.

Subscriptions, orders for back numbers, and changes of address should be sent to Pacific Journal of Mathematics, 103 Highland Boulevard, Berkeley, California, 94708.

PUBLISHED BY PACIFIC JOURNAL OF MATHEMATICS, A NON-PROFIT CORPORATION

Printed at Kokusai Bunken Insatsusha (International Academic Printing Co., Ltd.), 7-17, Fujimi 2-chome, Chiyoda-ku, Tokyo, Japan. 


\section{Pacific Journal of Mathematics}

\section{Vol. 31, No. $3 \quad$ BadMonth, 1969}

George E. Andrews, On a calculus of partition functions .................. 555

Silvio Aurora, A representation theorem for certain connected rings ............ 563

Lawrence Wasson Baggett, A note on groups with finite dual spaces ............. 569

Steven Barry Bank, On majorants for solutions of algebraic differential equations in regions of the complex plane ............................... 573

Klaus R. Bichteler, Locally compact topologies on a group and the corresponding continuous irreducible representations ......................... 583

Mario Borelli, Affine complements of divisors ....................... 595

Carlos Jorge Do Rego Borges, A study of absolute extensor spaces ............. 609

Bruce Langworthy Chalmers, Subspace kernels and minimum problems in Hilbert

spaces with kernel function ...................................... 619

John Dauns, Representation of L-groups and F-rings................. 629

Spencer Ernest Dickson and Kent Ralph Fuller, Algebras for which every

indecomposable right module is invariant in its injective envelope ...........

Robert Fraser and Sam Bernard Nadler, Jr., Sequences of contractive maps and fixed

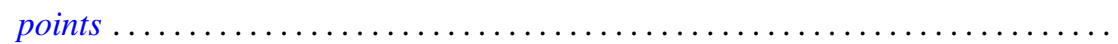

Judith Lee Gersting, A rate of growth criterion for universality of regressive

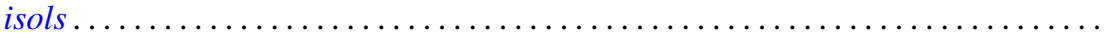

Robert Fred Gordon, Rings in which minimal left ideals are projective ............

Fred Gross, Entire functions of several variables with algebraic derivatives at certain algebraic points

W. Charles (Wilbur) Holland Jr. and Stephen H. McCleary, Wreath products of ordered permutation groups .........................

W. J. Kim, The Schwarzian derivative and multivalence .................. 717

Robert Hamor La Grange, Jr., On $(\mathrm{m}-\mathrm{n})$ products of Boolean algebras ......... 725

Charles D. Masiello, The average of a gauge ........................ 733

Stephen H. McCleary, The closed prime subgroups of certain ordered permutation

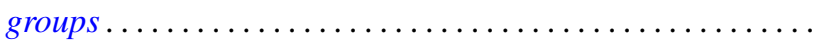

Richard Roy Miller, Gleason parts and Choquet boundary points in convolution measure algebras ...............................

Harold L. Peterson, Jr., On dyadic subspaces ........................ 773

Derek J. S. Robinson, Groups which are minimal with respect to normality being intransitive........................................... 777

Ralph Edwin Showalter, Partial differential equations of Sobolev-Galpern type . . . 787

David Slepian, The content of some extreme simplexes ................... 795

Joseph L. Taylor, Noncommutative convolution measure algebras ............. 809

B. S. Yadav, Contractions of functions and their Fourier series ............... 827

Lindsay Nathan Childs and Frank Rimi DeMeyer, Correction to automorphisms of separable algebras" ....................... 833

Moses Glasner and Richard Emanuel Katz, Correction to: "Function-theoretic degeneracy criteria for Riemannian manifolds".............

Satish Shirali, Correction to: "On the Jordan structure of complex Banach

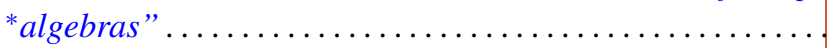

